\title{
Comparative Study of Septoplasty Alone and with FESS in Maxillary Sinusitis with Septal Deviation
}

\author{
Anuj Kumar Goel, SPS Yadav, Rupender Ranga, JS Gulia, Rati Goel
}

\begin{abstract}
Introduction: The study was conducted to asses if septoplasty is adequate for the management of chronic maxillary sinusitis. Chronic maxillary sinusitis is not uncommonly associated with deviated nasal septum (DNS). The randomized study was conducted on 40 cases of medically unmanageable and HRCT proven chronic maxillary sinusitis with DNS.
\end{abstract}

Materials and methods: The study was conducted in 40 cases of HRCT (PNS) proven chronic maxillary sinusitis which were not cured with medical treatment. The patients were divided randomly in two groups. Group A underwent septoplasty and group B septoplasty along with FESS in the form of uncinectomy and middle meatus antrostomy. Patients having other anatomical factors for example concha were excluded.

Results: Both procedures produced significant improvement in symptomatology and on HRCT (PNS) findings as compared to preoperative status ( $p$-value less than 0.001). Septoplasty was found to be effective in chronic maxillary sinusitis, however, when polyps were present in maxillary sinus, then septoplasty with FESS was found to be better.

Discussion: In cases of chronic maxillary sinusitis with DNS, septoplasty is adequate, however if the maxillary sinus shows polyps on HRCT (PNS) scan then septoplasty should be combined with FESS.

Keywords: Sinusitis, Septal deviation.

How to cite this article: Goel AK, Yadav SPS, Ranga R, Gulia JS, Goel R. Comparative Study of Septoplasty Alone and with FESS in Maxillary Sinusitis with Septal Deviation. Clin Rhinol Int J 2012;5(1):19-24.

Source of support: Nil

Conflict of interest: None declared

\section{INTRODUCTION}

The nasal septum though primarily a support structure of the nose is also important in the nasal physiology. ${ }^{1}$ The lining mucous membrane of nasal chamber and that of the maxillary sinus are histologically alike and are continuous in the natural ostium, so chronic rhinosinusitis is thought to be a disease secondary to obstruction caused by anatomic anomalies and reactive mucosal engorgement. Subsequent to obstruction, inflammation occurs and with this, the morphology of the lining mucosa of nasal sinus changes. ${ }^{2}$ As regional anatomic abnormalities and pathologies in the vicinity of osteomeatal complex (OMC) are frequently associated in the development of chronic sinus disease, Messerklinger identified a range of normal anatomic variants that can interfere with the mucocilliary drainage of the OMC including an enlarged middle turbinate, agger nasi cells, ethmoid bulla variation, Haller cells, spurs and deviated nasal septum. ${ }^{3}$ Bayiz et al observed the correlation of deviated nasal septum with chronic sinusitis and adequacy of septoplasty for treatment of chronic sinusitis. ${ }^{4}$ Coronal CT has become investigation of choice to diagnose chronic sinusitis as it simulates endoscopist's view of sinonasal cavity. ${ }^{5}$ Treatment modalities for chronic maxillary sinusitis are medical and surgical management. Medical management includes antibiotics, mucolytic agents, decongestants and antihistamines for appropriate duration. Surgical management includes antral lavage, intranasal antrostomy, Caldwell-Luc's operation ${ }^{6}$ and functional endoscopic sinus surgery. ${ }^{7}$ Treatment of the maxillary sinusitis by opening and irrigating the sinus via a variety of routes has a long and varied history. Highmore himself advocated decompression by thrusting a silver bodkin through an empty tooth socket. Many of the earliest writers, such as Cowper in 1707 and Meibomius in 1718, recommended irrigation through the alveolar tooth margin after molar tooth extraction. Zuckerkandl initially advocated perforation of the middle meatus, but later abandoned the technique because of potential of orbital damage. It is of interest that sporadic interest continued in middle meatus antrostomy, predating the introduction of endoscopic visualization. Mickulicz in 1887 and Lichtwitz in 1890, using trocar and stylette respectively began the first attempts at diagnosis by proof puncture followed by irrigation. More radical approach described by Caldwell ${ }^{8}$ in 1893.This situation pertained up to early 1980s in the UK when endoscopic surgery first made its appearance. The present study was planned to compare the adequacy of septoplasty alone vis-à-vis septoplasty with FESS in patients of chronic maxillary sinusitis with septal deviation.

\section{MATERIALS AND METHODS}

In the present study 40 cases of either sex in the age group of 18 to 50 years suffering from chronic maxillary sinusitis with septal deviation were included in the study. The patients were randomly divided into two groups of 20 each. Group A underwent septoplasty alone whereas patients of group B underwent septoplasty along with FESS. While selecting the patients of maxillary sinusitis for the study following criteria were observed. Patients with history of nasal obstruction, postnasal drip, nasal discharge, significant deviated nasal septum, HRCT (PNS) scan proven chronic 
maxillary sinusitis were included, whereas patients having nasal polyps (on rhinoscopy), nasal mass, previous nasal or sinus surgery, patients having skin disease of the nose including vestibule, any bleeding disorder, diabetes mellitus and hypertension were excluded from the study. Initial patient workup by detailed history about the symptoms and their duration, any preoperative treatment taken, detailed clinical examination (anterior rhinoscopy, posterior rhinoscopy, throat and ear examination) was done. All the patients were given 6 weeks of medical treatment in the form of broad spectrum antibiotics, antihistaminics and local as well as systemic decongestants. The patients showing no improvement were subjected to X-ray paranasal sinuses occipitomental view and cases with hazy sinuses were subjected to HRCT (PNS) coronal and axial view. The patients having involvement of only maxillary sinuses were taken up for study. Routine blood and urine tests were done in all the patients. The patients were admitted in the ward a day prior to surgery and kept fasting after midnight. Written informed consent was taken and xylocaine sensitivity was done. In group a patients where only septoplasty was done. Hemitransfixation incision $2 \mathrm{~mm}$ posterior to caudal edge of septum were made after injecting local anesthesia, then between cartilage and perichondrium an anterior tunnel was made on both sides. If necessary inferior tunnel was also made. Extreme precaution was taken to avoid mucosal disruption during tunneling. After tunneling inferior part of septum was detached from anterior nasal spine, premaxilla and maxillary crest. Now cartilage and bony septum was separated by making an incision at posterior end of cartilaginous septum. Now correction of septal pathology by removing inferior strip of septum to relieve septal tension or fracturing and repositioning bony septum or by resecting the parts of septum was made. After correcting deviation suturing of incision by 3-0 chromic catgut was done and merocel anterior nasal packing was done on both side. In group B patients after injecting local anesthesia septoplasty was performed as in group A patients. After septoplasty a 0-degree 4-mm Hopkins rod telescope used for the endoscopic surgery. An infundibulotomy was performed by incising the anterior attachment of the uncinate process with a sickle knife to display the infundibulum and it is then grasped with forceps, the upper and lower attachments cut with fine scissors, and the process detached with twisting movement with care to avoid damage to nasolacrimal duct and mucosa. Middle meatal antrostomy was done only if maxillary ostium was not found patent. If the ostium was not visible after uncinectomy, palpation of the lateral wall with ' $\mathrm{J}$ ' curette or curved sucker was made to identify ostium position. Once identified, ostium was enlarged using forward biting and back biting forceps. No irrigation of sinuses was done to avoid bias as irrigation was not done in group A patients. Now septal incision was stitched and bilateral merocel anterior nasal packing was done. Patients were discharged on the second day of surgery after pack removal. All patients were put on oral antibiotics, analgesics, antihistaminics, alkaline nasal douching, steriod nasal spray and decongestant nasal drops postoperatively for 10 days. The follow-up was done at 1st week, 6th week and 12th week. At 12th week follow-up HRCT (PNS) coronal and axial view was also done. Patients were reviewed for their symptoms relief subjectively using visual analog scale and objectively by clinical examination and HRCT (PNS) scans. Postoperative improvement in symptoms at 12th week by VAS score in both the groups was compared statistically by using student t-test.

\section{RESULTS}

Age of the patients was in the range of 18 to 50 years. Mean age in group A was 26.7 years while mean age of group B was 29.1 years. Out of 40 patients, 17 were males and 23 were females. Nasal obstruction and postnasal drip were present in all patients and rhinorrhea and nasal discharge were other common symptoms (Table 1). Most of the patients (19) were suffering from the symptoms for more than 3 years (47.5\%); 10 (25\%) for 6 months to 1 year; 6 (15\%) patients had symptoms for 2 to 3 years and 5 (12.5\%) for 1 to 2 years. Anterior rhinoscopy revealed deviated nasal septum in all the 40 (100\%) patients. Other significant findings were discharge in the middle meatus and hypertrophy of inferior turbinate in posterior rhinoscopy most common finding was posterior nasal discharge seen in 24 (60\%) patients, 12 (30\%) patients in each group. Hypertrophy of posterior end of inferior turbinate was another common finding. Postnasal drip and congestion of posterior pharyngeal wall were major clinical findings on oral examination in 20 (50\%) and 17 (42.5\%) patients in group A and B respectively. HRCT scan (PNS) coronal and

Table 1: Symptomatology $(n=40)$

\begin{tabular}{|c|c|c|c|c|c|c|}
\hline \multirow[t]{2}{*}{ Symptoms } & \multicolumn{2}{|c|}{ Group A } & \multicolumn{2}{|c|}{ Group B } & \multicolumn{2}{|c|}{ Total } \\
\hline & No. & $\%$ & No. & $\%$ & No. & $\%$ \\
\hline Nasal obstruction & 20 & 50 & 20 & 50 & 40 & 100 \\
\hline Postnasal drip & 20 & 50 & 20 & 50 & 40 & 100 \\
\hline Rhinorrhea & 18 & 45 & 18 & 45 & 36 & 90 \\
\hline Nasal discharge & 16 & 40 & 20 & 50 & 36 & 90 \\
\hline
\end{tabular}


axial view was done in all the cases. OMC obstruction was the most common finding in 39 (97.5\%) patients. Mucosal hypertrophy of maxillary sinus was the next most common finding in 28 (70\%) patients. Polypoidal change in maxillary sinus mucosa was seen in 13 (32.5\%) patients. All the patients were having significant deviated nasal septum (Table 2). In patients having only deviated nasal septum without any hypertrophy of inferior turbinates, there was no difference in the left and right maxillary sinus infection rate depending on the side of deviated nasal septum, however, when deviated nasal septum was having inferior turbinate hypertrophy of opposite side than this lead to involvement of sinuses of both side. At 12 weeks followup in group A, out of 20 patients with nasal obstruction 13 had $100 \%$ relief, five patients had $90 \%$ relief and two patients had $80 \%$ relief as per VAS. Nine patients out of 20 with postnasal drip had $70 \%$ improvement, seven patients out of 18 with rhinorrhea had 90\% improvement and six patients out of 16 with nasal discharge had $80 \%$ improvement whereas at 12 weeks follow-up in group B, out of 20 patients with nasal obstruction 17 had $100 \%$ relief, one patient each had 90, 80, 70\% relief respectively as per VAS. Nine patients out of 20 with postnasal drip had 70\% improvement, eight patients had 80\% improvement in nasal discharge and seven patients out of 18 had $80 \%$ improvement in rhinorrhea. Postoperative assessment by diagnostic nasal endoscopy in group A $(n=20)$ at 6 and 12 week follow-up shown midline septum, with no inferior turbinate hypertrophy. Only three patients out of 20 had discharge in nasal cavity. Postoperative assessment by diagnostic nasal endoscopy in group $B(n=20)$ at 6 and 12 weeks follow-up shown midline septum, with patent middle meatus antrostomy. However, at 6th week four patients out of 20 had discharge in nasal cavity, while at 12th week only three patients had discharge in nasal cavity. Improvement in the symptoms was compared in both the groups after 12 weeks and it was found to be statistically very highly significant $(p<0.001)$. In group A, complete eradication of symptoms, i.e. VAS 100 was achieved by 13 out of 20 patients with nasal obstruction, one out of 20 patients with postnasal drip, one out of 18 patients with rhinorrhea and one out of 16 patients with nasal discharge, whereas in group B $100 \%$ score was achieved by 17 out of 20 patients with nasal obstruction, one out of 20 patients with postnasal drip, one out of 20 patients with nasal discharge (Table 3). Postoperative assessment by HRCT (PNS) scan of group A and B patients $(n=40)$ shown that all patients of group A had septum in midline. Seven patients had polypoidal mucosa in maxillary sinus, eight patients had OMC obstruction while none had mucosal hypertrophy in maxillary sinus. While group B patients had shown that all had septum in midline, with no evidence of antral polypoidal changes or OMC obstruction. Only one patient had mucosal hypertrophy in maxillary sinus (Table 4). No complications were observed in group A, however, seven cases developed synechie in group B which were removed and at 6th weeks.

\section{DISCUSSION}

Chronic sinusitis is one of the commonest medical problem in ENT practice and maxillary sinus is the commonest to

\begin{tabular}{|c|c|c|c|c|c|c|c|c|}
\hline \multirow[t]{2}{*}{ HRCT findings } & \multicolumn{3}{|c|}{ Group A } & \multicolumn{3}{|c|}{ Group B } & \multicolumn{2}{|c|}{ Total } \\
\hline & $\begin{array}{c}\text { Unilateral } \\
\text { No. (\%) }\end{array}$ & $\begin{array}{l}\text { Bilateral } \\
\text { No. (\%) }\end{array}$ & $\begin{array}{c}\text { Total } \\
\text { No. (\%) }\end{array}$ & $\begin{array}{c}\text { Unilateral } \\
\text { No. (\%) }\end{array}$ & $\begin{array}{l}\text { Bilateral } \\
\text { No. (\%) }\end{array}$ & $\begin{array}{c}\text { Total } \\
\text { No. (\%) }\end{array}$ & No. & $\%$ \\
\hline Mucosal hypertrophy & $6(15)$ & $6(15)$ & $12(30)$ & $4(10)$ & $12(30)$ & $16(40)$ & 28 & 70 \\
\hline OMC obstruction & $8(20)$ & $12(30)$ & $20(50)$ & $4(10)$ & $15(37.5)$ & $19(47.5)$ & 39 & 97.5 \\
\hline Polyp & $6(15)$ & $2(5)$ & $8(20)$ & $5(12.5)$ & 0 & $5(12.5)$ & 13 & 32.5 \\
\hline Deviated nasal septum & - & - & $20(50)$ & - & - & $20(50)$ & 40 & 100 \\
\hline
\end{tabular}

\begin{tabular}{|c|c|c|c|c|c|c|}
\hline \multirow[t]{2}{*}{ Symptoms } & \multirow[t]{2}{*}{ No. of patients } & \multicolumn{2}{|c|}{ Total improvement in group A } & \multirow{2}{*}{$\begin{array}{c}\text { Total no. of } \\
\text { patients }\end{array}$} & \multicolumn{2}{|c|}{ Total improvement in group $B$} \\
\hline & & No. of patients & Score & & No. of patients & Score \\
\hline \multirow[t]{3}{*}{ Nasal obstruction } & 20 & 13 & 100 & 20 & 17 & 100 \\
\hline & & 5 & 90 & - & 1 & 90 \\
\hline & & 2 & 80 & - & 2 & $\geq 70$ \\
\hline \multirow[t]{3}{*}{ Postnasal drip } & 20 & 1 & 100 & 20 & 1 & 100 \\
\hline & & 6 & $\geq 80$ & - & 15 & $\geq 80$ \\
\hline & & 13 & $\geq 60$ & - & 4 & $\geq 50$ \\
\hline \multirow[t]{3}{*}{ Rhinorrhea } & 18 & 1 & 100 & 18 & 4 & 90 \\
\hline & & 11 & $\geq 80$ & - & 7 & 80 \\
\hline & & 6 & $\geq 50$ & - & 7 & $\geq 60$ \\
\hline \multirow[t]{3}{*}{ Nasal discharge } & 16 & 1 & 100 & 20 & 1 & 100 \\
\hline & & 9 & $\geq 80$ & - & 7 & 90 \\
\hline & & 6 & $\geq 50$ & - & 12 & $\geq 70$ \\
\hline
\end{tabular}


be involved. Chronic sinusitis is a clinical diagnosis and is defined as a rhinosinusitis lasting $>12$ weeks that includes two or more major sinus symptoms or at least one major and two minor sinus symptoms with or without findings on physical examination. Major symptoms are facial pain/ pressure, facial congestion/fullness, nasal obstruction/ blockage, nasal discharge, hyposmia/anosmia, prulence in nasal cavity on examination and fever (in acute rhinosinusitis only). Minor symptoms are headache, fever, halitosis, fatigue, dental pain, cough and ear pain/pressure/ fullness (all nonacute). Imaging is indicated only after adequate medical treatment, therefore imaging should be interpreted in light of history, examination and response to medical treatment. ${ }^{9}$ Although CT provides information about the extent of mucosal disease, several studies have failed to correlate CT findings with symptoms severity at the time of presentation. ${ }^{10}$ Examination of these patients may reveal other findings, such as nasal allergy, polyposis and anatomical abnormalities which predispose to sinusitis. The present study revealed male predominance over females as reported earlier. ${ }^{11,12}$ The males are often exposed to inclemencies of the environment hence are more affected. Common symptoms in present study were nasal obstruction and postnasal drip (100\% each). Next in frequency were nasal discharge and rhinorrhea (90\% each). Symptomatology in present study is comparable to that in a study by Kennedy. ${ }^{13}$ Salam and Cable observed postnasal discharge (88.2\%), nasal obstruction (84.3\%), headache (78.4\%) and hyposmia (11.76\%) as major symptoms in their study of 51 patients. ${ }^{14}$ Besides the clinical and radiological findings the duration of symptoms is very important for diagnosis. Lund et al ${ }^{15}$ used more than 8 weeks persistent symptoms and signs as a criteria for chronic sinusitis. Litton $^{16}$ and Van Cauwonberge ${ }^{17}$ suggested a time interval of 3 months whereas Benninger suggested inflammation of the mucosa of the nose and paranasal sinuses of at least 12 consecutive weeks. ${ }^{18}$ In the present study most of the patients (47.5\%) suffered from the disease for a much longer time, i.e. more than 3 years and none less than 6 months. Common clinical signs in patients in the present study were deviated nasal septum (100\%), posterior nasal drip (60\%), nasal discharge (55\%), congested posterior pharyngeal wall (42.5\%) and hypertrophy of inferior turbinate (30\%). Sinha ${ }^{12}$ reported presence of mucus or mucopus in middle meatus in $76 \%$ in his series of 42 patients. Prabhakar et $\mathrm{al}^{19}$ in their study of 75 patients of chronic maxillary sinusitis found nasal discharge in $69 \%$, septal deviation in $51 \%$, inferior turbinate hypertrophy in $52 \%$ and congestion of posterior pharyngeal wall in $29 \%$. CT scan with its excellent capability for displaying bone and soft tissues, is the current diagnostic modality of choice for evaluating the OMC and provides precise guidance for therapeutic endoscopic instrumentation. ${ }^{20}$ In the present study most common HRCT (PNS) scan finding was deviated nasal septum $100 \%$. Other findings in descending order were OMC obstruction (97.5\%), mucosal hypertrophy (70\%) and maxillary antrum polypoidal mucosa (32.5\%). The mucosal changes in the present study is comparable to earlier studies. ${ }^{11,21,22}$ In the present study septoplasty was done in 20 patients of group A. The patients improved symptomatically as assessed by VAS. Postoperative symptomatic improvement in the symptoms at 12 weeks was found to be highly significant ( $\mathrm{p}<0.001$ ). Postoperative assessment by HRCT (PNS) at 12th week revealed that none of the patients had any mucosal hypertrophy but patients who were having maxillary antrum polypoidal changes or OMC obstruction had little effect of the septoplasty alone (Table 4). In group B septoplasty with FESS was done in 20 patients. There were postoperative adhesions at 1st week follow-up in seven (17.5\%) patients which were released. Patients improved symptomatically as assessed by VAS. Postoperative symptomatic improvement in the symptoms at 12 weeks was found to be very highly significant $(p<0.001)$. Postoperative assessment by HRCT (PNS) at 12th week had shown that all the patients had no abnormalities in maxillary or OMC region (Table 4).

Chronic rhinosinusitis is thought to be a disease secondary to obstruction caused by anatomic anomalies and reactive mucosal engorgement. The goal of treating sinus disease with surgery has evolved from removing all diseased sinus mucosa to specific exenteration of the tissue causing obstruction. Once ventilation is restored, it is postulated that the mucosa may regain near normal appearance and function. Regional anatomic abnormalities and pathologic

Table 4: HRCT scan PNS finding $(n=40)$

\begin{tabular}{|c|c|c|c|c|c|c|c|c|}
\hline \multirow[t]{2}{*}{ HRCT findings } & \multicolumn{4}{|c|}{ Group A } & \multicolumn{4}{|c|}{ Group B } \\
\hline & $\begin{array}{c}\text { Right } \\
\text { No. (\%) }\end{array}$ & $\begin{array}{c}\text { Left } \\
\text { No. (\%) }\end{array}$ & $\begin{array}{l}\text { Bilateral } \\
\text { No. (\%) }\end{array}$ & $\begin{array}{c}\text { Total } \\
\text { No. (\%) }\end{array}$ & $\begin{array}{l}\text { Right } \\
\text { No. (\%) }\end{array}$ & $\begin{array}{c}\text { Left } \\
\text { No. (\%) }\end{array}$ & $\begin{array}{l}\text { Bilateral } \\
\text { No. (\%) }\end{array}$ & $\begin{array}{c}\text { Total } \\
\text { No. (\%) }\end{array}$ \\
\hline Mucosal hypertrophy & $0(0)$ & $0(0)$ & $0(0)$ & $0(0)$ & $0(0)$ & $1(2.5)$ & $0(0)$ & $1(2.5)$ \\
\hline OMC obstruction & $1(2.5)$ & $2(5)$ & $5(12.5)$ & $8(20)$ & $0(0)$ & $0(0)$ & $0(0)$ & $0(0)$ \\
\hline Polyps & $0(0)$ & $5(12.5)$ & $2(5)$ & $7(17.5)$ & $0(0)$ & $0(0)$ & $0(0)$ & $0(0)$ \\
\hline Deviated nasal septum & $0(0)$ & $0(0)$ & $0(0)$ & $0(0)$ & $0(0)$ & $0(0)$ & $0(0)$ & $0(0)$ \\
\hline
\end{tabular}


processes in the vicinity of the OMC predispose in the development of chronic sinus disease. Messerklinger identified a range of normal anatomic variants that can interfere with mucocilliary drainage of the OMC including an enlarged concha bullosa, a deviated uncinate process, paradoxical middle turbinate, agger nasi cell, ethmoidal bulla variations, Haller cell, spurs and deviated nasal septum. ${ }^{3}$ Deviated nasal septum causes different airflow dynamics in the nasal cavities which leads to development of compensatory hypertrophy of nasal mucosa of the opposite side of deviated nasal septum. ${ }^{23}$ Deviated nasal septum leads to increased chance of impaired mucocilliary clearance, OMC obstruction and development of sinusitis ${ }^{24}$ and sinusitis is more severe on opposite side of deviated nasal septum. ${ }^{25}$ Jin et al proposed classification system for deviated nasal septum on basis of its morphology, site, severity and influence of septal deviation on external nose by classifying septal deviation into four types. Type 1 was having localized deviation, type 2 having curved/angulated deviation, type 3 having curved/angulated deviation combined with type 1 , and in type 4 curved/angulated deviation with associated dorsal nasal deviation. ${ }^{26}$ There are several studies related to correlation of septal deviation and sinusitis. Yousem et al evaluated the morphologic features that predispose to sinusitis, and concluded that patients with evidence of sinusitis on CT scanning had a higher degree of septal deviation. They observed that nasal septal deviation affects both ipsilateral and contralateral sinuses. ${ }^{27}$ Calhoun et al examined the paranasal sinus CT images of both asymptomatic and symptomatic patients and found a strong correlation between septal deviation and sinus disease. ${ }^{28}$ Elahi et al studied OMC region in 122 patients with DNS and correlated the data with paranasal sinus disease, lateral nasal wall finding and middle turbinate abnormalities. They observed that OMC obstruction in the direction of septal angulation was due to nasal septal deformity while contralateral OMC obstruction was related to middle turbinate and lateral nasal wall abnormalities which appeared with increased frequency on the side opposite of septal deviation. ${ }^{3}$ Tao et al explored the influence of the deviated septum on the OMC. They examined 103 patients with nasal deviation by nasal endoscopy and their paranasal sinus CT scans and evaluated incidence of sinusitis on either side of deviated nasal septum and found no difference between the incidence of sinusitis on the two sides. $^{29}$

Bayiz et al studied 26 patients to reveal the role of septoplasty in curing chronic rhinosinusitis in patients with significant septal deviation by dividing them randomly into two groups. In the first group septoplasty alone was done whereas second group underwent septoplasty with FESS. The success rate in first group was $93.3 \%$ while of second group was $81.8 \%$. So they suggested that septoplasty alone can be adequate for the treatment of chronic rhinosinusitis in patients with deviated nasal septum. ${ }^{4}$ In the present study it was observed that septoplasty alone is adequate in patients with chronic maxillary sinusitis with hypertrophy of antral mucosa, however, there was no effect on maxillary antrum polypoidal mucosa. On the other hand, septoplasty with FESS has given excellent result but in expert hands only. In conclusion septoplasty alone is adequate in patients with limited sinus disease, e.g. mucosal hypertrophy in maxillary sinus with septal deviation whereas if there are antral polypoidal changes FESS should be undertaken simultaneously.

\section{REFERENCES}

1. Uygur K, Tuz M, Dogru H. The correlation between septal deviation and concha bullosa. Otolaryngol Head Neck Surg 2003;129:33-36.

2. Havas TE, Lowinger DSG. Comparison of functional endonasal sinus surgery with and without partial middle turbinate resection. Ann Otol Rhinol Laryngol 2000;109:634-40.

3. Chakares DW. Computed tomography of the ethmoid sinuses. Otolaryngol Clin North Am 1985;18:29-42.

4. Bayiz U, Dursun E, Islam A, Korkmaz H, Arslan N, Ceylan K, et al. Is septoplasty alone adequate for the treatment of chronic rhinosinusitis with septal deviation? Am J Rhinol 2005;19(6): 612-16.

5. Yousem DM. Imaging of sinonasal inflammatory disease. Radiology 1993;188:303-14.

6. Macbeth R. Caldwell-luc's operation 1952-1966. Arch Otolaryngol 1968;87:630-36.

7. Kennedy DW. Functional endoscopic sinus surgery - technique. Arch Otolaryngol 1985;111:643-49.

8. Caldwell GW. Diseases of the accessory sinuses of the nose and an improved method of treatment of suppuration of the maxillary antrum. New Journal Medical J 1893:58:526-28.

9. Lanza DC, Kennedy DW. Adult rhinosinusitis defined. Otolaryngol Head Neck Surg 1997;117(3):S1-7.

10. Bhattacharya T, Piccirollo J, Wippold FJ II. Relationship between patient-based descriptions of sinusitis and paranasal sinus computed tomographic findings. Arch Otolaryngol Head Neck Surg 1997;123:1189-92.

11. Bolger WE, Butzin CA, Parson DS. Paranasal sinus bony anatomic variations and mucosal abnormalities: CT analysis for endoscopic sinus surgery. Laryngoscope 1991;101:56-64.

12. Sinha DK. Nasal and sinus endoscopy in opaque maxillary antrum. Indian J Otolaryngol Head Neck Surg 1993;145:145-46.

13. Kennedy DW. Prognostic factors, outcomes and staging in ethmoid sinus surgery. Laryngoscope 1992;102:1-18.

14. Salam MA, Cable HR. Middle meatal antrostomy: Long term patency and results of chronic maxillary sinusitis. A prospective study. Clin Otolaryngol 1993;18:135-38.

15. Lund VJ, Kennedy DW. Staging of rhinosinusitis. Otolaryngol Head Neck Surg 1997;117:535-40.

16. Litton W. Acute and chronic sinusitis. Otolaryngol Clin N Am 1971;4:25. 
17. Van Cauwonberge P. Medikamenteuze behandeling Van sinusitis. Acta Otol Rhinol Laryngol Belg 1983;37:614-23.

18. Benninger MS. Adult chronic rhinosinusitis: Definitions, diagnosis, epidemiology and pathophysiology. Otolaryngol Head Neck Surg 2003;129:1-32.

19. Prabhakar S, Mehra YN, Talwar P, Mann SBS, Mehta SK. Fungal infections in maxillary sinusitis. Indian J Otolaryngol Head Neck Surg 1992; 1(2): 57-7.

20. Zinreich SJ, Kennedy DW, Rosenbaum AE. Paranasal sinuses: CT imaging requirements for endoscopic surgery. Radiology 1987;163:769-75.

21. Stoney P, Probst L, Shanker L. CT scanning for functional endoscopic sinus surgery: Analysis of 200 cases with reporting scheme. J Otolaryngol 1993;22:72-78.

22. Elahi M, Frenkiel S, Remy H, Just N, Haddad M. Development of a standardized proforma for reporting computerized tomography images of paranasal sinuses. J Otolaryngol 1996; 25:113-20.

23. Ilium P. Septoplasty and compensatory inferior turbinate hypertrophy: Long term results after randomized turbinoplasty. Eur Arch Otorhinolaryngol 1997;1:89-92.

24. Ginzel A, Ilium P. Nasal mucociliary clearance in patients with septal deviation.Rhinology 1980;18:177-81.

25. Suzuki H, Yamaguchi T, Furukawa M. Rhinologic computed tomographic evaluation in patients with cleft lip and palate. Arch Otolaryngol Head Neck Surg 1999;125:1000-04.

26. Jin HR, Lee JY, Jung WJ. New description method and classification system for septal deviation. J Rhinol May 2007;14(1):27-31.

27. Yousem DM, Kennedy DW, Rosenberg S. Ostiomeatal complex risk factors for sinusitis: CT evaluation. J Otolaryngol 1991; 20:419-24.
28. Calhoun KH, Waggenspack GA, Simpson CB. CT evaluation of the paranasal sinuses in symptomatic and asymptomatic populations. Otolaryngol Head Neck Surg 1991;104:480-83.

29. Tao Z, Zhang J, Yang Q, Xiao B, Kong Y. Differences of anatomic variations in ostiomeatal complex between two sides of the deviated septum. Zhonghua Er Bi Yan Hou Ke Za Zhi 2001;36(2):132-34.

\section{ABOUT THE AUTHORS}

\section{Anuj Kumar Goel (Corresponding Author)}

Assistant Professor, Department of Otorhinolaryngology, Saraswathi Institute of Medical Sciences, Hapur-245101, Ghaziabad, Uttar Pradesh, India, e-mail: dranujgoel@rediffmail.com

\section{SPS Yadav}

Senior Professor, Department of Otorhinolaryngology, Postgraduate Institute of Medical Sciences, Rohtak, Haryana, India

\section{Rupender Ranga}

Director, Bharat ENT and Endoscopic Hospital, Bhiwani, Haryana, India

\section{JS Gulia}

Associate Professor, Department of Otorhinolaryngology Postgraduate Institute of Medical Sciences, Rohtak, Haryana, India

\section{Rati Goel}

Senior Resident, Department of Otolaryngology, Saraswathi Institute of Medical Sciences, Hapur, Ghaziabad, Uttar Pradesh, India 